\title{
Role of Cu film texture in grain growth correlated with twin boundary formation
}

\section{$\operatorname{AUTHOR}(S)$ :}

Kohama, Kazuyuki; Ito, Kazuhiro; Matsumoto, Takuya; Shirai, Yasuharu; Murakami, Masanori

\section{CITATION:}

Kohama, Kazuyuki ... [et al]. Role of Cu film texture in grain growth correlated with twin boundary formation. Acta Materialia 2012, 60(2): 588-595

\section{ISSUE DATE:}

2012-01

URL:

http://hdl.handle.net/2433/153029

\section{RIGHT:}

(C) 2011 Acta Materialia Inc. Published by Elsevier Ltd.; This is not the published version. Please cite only the published version.; この論文は 出版社版でありません。引用の際には出版社版をご確認ご利用くださ い。 


\section{Role of Cu Film Texture in Grain Growth Correlated to Twin Boundary}

\section{Formation}

Kazuyuki Kohama, ${ }^{\text {a, }}$, Kazuhiro Ito ${ }^{\mathrm{a}}$, Takuya Matsumoto ${ }^{\mathrm{a}}$, Yasuharu Shirai ${ }^{\mathrm{a}}$, and Masanori Murakami ${ }^{\text {b }}$

${ }^{a}$ Department of Materials Science and Engineering, Kyoto University, Yoshida-Honmachi, Sakyo-ku, Kyoto 606-8501, Japan

${ }^{b}$ The Ritsumeikan Trust, Nakagyo-ku, Kyoto 604-8520, Japan

Corresponding Author: Kazuyuki Kohama

TEL: +81-75-753-5482 / FAX: +81-75-753-3579

*E-mail address: k.kohama@eng.mbox.media.kyoto-u.ac.jp 


\section{ABSTRACT}

To understand the role of $\mathrm{Cu}$ film texture in grain growth at room temperature (RT) in relation to twin boundary formation, $\mathrm{Cu}$ films were deposited on various barrier materials, and $\mathrm{Cu}$ film texture was investigated by $\mathrm{X}$-ray diffraction. The $\mathrm{Cu}$ grain growth was rapid on the barrierless $\mathrm{SiO}_{2} / \mathrm{Si}$ substrate, and very slow on the Ta barrier due to strong (111) texture. The growth rate and the average grain diameter after keeping at RT up to $\sim 60$ days were maximized at the $(200)_{\mathrm{Cu}}$ peak to $(222)_{\mathrm{Cu}}$ peak area ratio of $\sim 1.0$, where the $\{111\},\{100\}$, and $\{511\}$ grains coexisted. Such coexistence of three or more orientations of grains is essential for facilitating $\mathrm{Cu}$ grain growth at $\mathrm{RT}$. Similarly, average twin boundary (TB) density was maximized when $\mathrm{Cu}$ grain growth was facilitated. The TB formation in nano-sized $\mathrm{Cu}$ grains was not controlled by grain size, but caused by grain growth. The TBs could be annealing twins caused by irregularities in stacking sequence during relatively fast grain growth. The $\mathrm{Cu}$ film texture is concluded to be determined at the early beginning of deposition, and wettability of various barrier materials to the $\mathrm{Cu}$ films plays a key role in determining the film texture.

Keywords: thin films; sputtering; texture; abnormal grain growth; twinning 


\section{Introduction}

As the widths of $\mathrm{Cu}$ wires reduce to a deep sub-micron scale in ultra-large scale integrated (ULSI) devices, a large resistance-capacitance delay is becoming a critical material-related issue [1]. One of the primary factors for the increase in electrical resistivity of the $\mathrm{Cu}$ wires is the existence of fine $\mathrm{Cu}$ grains. Thus, understanding the mechanism of grain growth in $\mathrm{Cu}$ films is essential for reducing the resistivity increase. In the past two decades there have been many investigations on grain growth in $\mathrm{Cu}$ thin films, and both $\mathrm{Cu}$ grain growth and $\mathrm{Cu}$ texture were reported to be affected by diffusion-barrier materials [2-10]: Strong (111) texture was observed in $\mathrm{Cu}$ films deposited on barriers such as $\mathrm{Ta}$ and $\mathrm{Ti}$; in contrast, some (100)-oriented grains in addition to (111)-oriented grains were observed in $\mathrm{Cu}$ films on $\mathrm{W}$ and barrierless $\mathrm{SiO}_{2}$. The strong (111) texture suppressed $\mathrm{Cu}$ grain growth and that containing (100)-oriented grains among the (111) grains facilitated $\mathrm{Cu}$ grain growth.

On the other hand, many twin boundaries (TBs) were observed in $\mathrm{Cu}$ films. TBs with nano-sized spaces inside $\mathrm{Cu}$ grains are known to increase mechanical strength without ductility degradation, and to have little increasing effect on resistivity $[11,12]$. Since TBs are homogeneous, electrical resistivities of $\mathrm{TBs}$ are about one order of magnitude lower than those of high-angle grain boundaries [13]. TBs are also expected to increase electro-migration (EM) resistance when not oriented in parallel to $\mathrm{Cu}$ interconnects $[14,15]$. Thus, TBs are believed to be useful for nano-sized $\mathrm{Cu}$ interconnects in ULSI devices. However, TBs are known to form easily in $\mathrm{Cu}$ grains not only in films, but in bulk due to their relatively low stacking fault energy. There are three possible types of TB formation: growth twins $[11,12,16,17]$, annealing twins [18-21], and deformation twins [22-25]. Growth twins and annealing twins easily 
formed when deposition rates of $\mathrm{Cu}$ films and/or growth rates of $\mathrm{Cu}$ grains were fast (i.e., TB formation is the result of irregularities in stacking sequence). Furthermore, TBs of the growth twins are usually oriented in parallel to a film surface, and thus they are expected not to be useful for enhancing EM resistance. Hence, we focused on annealing twins, which we assumed probably correlates with the grain growth mentioned above.

In this study, $\mathrm{Cu}$ films were deposited on various barrier materials, and $\mathrm{Cu}$ film texture was investigated by X-ray diffraction (XRD). The texture was evaluated by the area ratio of a $(200)_{\mathrm{Cu}}$ peak to a $(222)_{\mathrm{Cu}}$ peak. To elucidate the degree to which $\mathrm{Cu}$ growth is facilitated in a specific range of the ratio, $\mathrm{Cu}$ grain growth was traced as a function of time kept at room temperature (RT) and was systematically characterized by the ratio. The $\mathrm{Cu}$ grain growth was represented by resistivity decrease in the $\mathrm{Cu}$ films. Simultaneously, to make correlation between the TB formation and the $\mathrm{Cu}$ grain growth clear, the TBs were observed in $\mathrm{Cu}$ films by scanning ion microscopy (SIM) and transmission electron microscopy (TEM) after keeping at RT. Finally, to explain $\mathrm{Cu}$ film texture variation with barrier materials, the wettability of various barrier films to deposited $\mathrm{Cu}$ films about $10 \mathrm{~nm}$ in thickness and the textures of the films were investigated.

\section{Experimental Procedure}

About $250 \mathrm{~nm}$-thick $\mathrm{Cu}$-film deposition followed various types of barrier deposition on $\mathrm{SiO}_{2} / \mathrm{Si}$ substrates in a radio frequency magnetron sputter system. Barrier samples were a $150 \mathrm{~nm}$-thick Ta or TaN layer, layers composed of $75 \mathrm{~nm}$-thick Ta and 75 nm-thick TaN as Ta/TaN or TaN/Ta, a 100 nm-thick Ti or TiN layer, and 50 nm-thick Ti and TiN as Ti/TiN or TiN/Ti. The Cu films were also deposited on barrierless substrates 
of $\mathrm{SiO}_{2} / \mathrm{Si}$ and (1120)-oriented sapphire. Prior to film deposition, the substrates were ultrasonically cleaned with acetone and isopropyl alcohol. Additionally, the sapphire substrate was cleaned with buffered hydrofluoric acid. The base pressure prior to deposition was approximately $1 \times 10^{-6} \mathrm{~Pa}$. The sputtering power was kept at $300 \mathrm{~W}$. The working pressure for pure metal $(\mathrm{Cu}, \mathrm{Ta}, \mathrm{Ti})$ deposition and for metal nitride $(\mathrm{TaN}, \mathrm{TiN})$ deposition was about $1 \mathrm{~Pa}$ and $0.5 \mathrm{~Pa}$, respectively. Ar gas and $\mathrm{Ar} / \mathrm{N}_{2}$ mixed gases were used for the pure metal depositions and for the metal nitride depositions, respectively. The substrate holder was placed $100 \mathrm{~mm}$ above the target. The purity of the $\mathrm{Cu}, \mathrm{Ta}$, and Ti targets was $99.99 \%$.

The resistivity and the texture of the $\mathrm{Cu}$ films were measured by van der Pauw method and XRD method, respectively. The (111) and (100) textures in the $\mathrm{Cu}$ films were evaluated by a conventional $\theta-2 \theta$ scan. The texture was represented by area ratio $(\alpha)$ of the $(200)_{\mathrm{Cu}}$ peak to the $(222)_{\mathrm{Cu}}$ peak in the $\theta-2 \theta$ spectra, which was estimated by peak fitting using two pseudo-Voigt functions corresponding to $\mathrm{K}_{\alpha 1}$ and $\mathrm{K}_{\alpha 2}$ peaks and the background [26]. The $(511)_{\mathrm{Cu}}$ peak is out of range of $2 \theta$ in the $\theta-2 \theta$ scan using the $\mathrm{Cu} \mathrm{K} \mathrm{K}_{\alpha}$-ray, and thus the (511) texture was evaluated by a $\theta$ scan, where $2 \theta$ was set to $50.5^{\circ}$, for example, as the angle corresponding with $(200)_{\mathrm{Cu}}$, and $\theta$ was changed in the range between $0^{\circ}$ and $50^{\circ}$. When [511] is perpendicular to the $\mathrm{Cu}$ film surface, two peaks were observed to be symmetric about $25^{\circ}$. Microstructures such as grain size and TBs in Cu films kept up to about 270 days at RT were observed by SIM and TEM. For plan-view TEM observation, specimens with thinned-down Ta barrier layers or $\mathrm{Cu}$ films were made as $\mathrm{Cu} / 5 \mathrm{~nm}$-thick $\mathrm{Ta} / \mathrm{SiO}_{2} / \mathrm{Si}$ or $20 \mathrm{~nm}$-thick $\mathrm{Cu} / \mathrm{SiO}_{2} / \mathrm{Si}$. Wettability of various barrier materials to the $\mathrm{Cu}$ films was investigated by atomic force microscope (AFM) using about $10 \mathrm{~nm}$-thick $\mathrm{Cu}$ films. 


\section{Results and Discussion}

\subsection{Room Temperature Grain Growth Depended on Film Texture}

Figures 1(a) and 1(b) show portions of XRD spectra around the $(200)_{\mathrm{Cu}}$ and

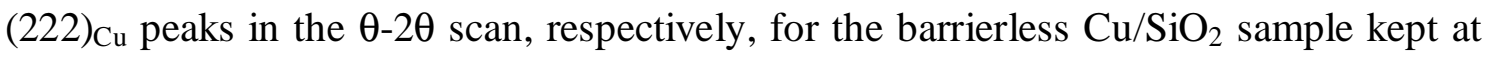
RT. Both $(200)_{\mathrm{Cu}}$ and $(222)_{\mathrm{Cu}}$ peak areas increased with increasing keeping time. The peak areas estimated by peak fitting are depicted as a function of keeping time in Figure 1(c). The estimated values for both $(200)_{\mathrm{Cu}}$ and (222) $\mathrm{Cu}$ peak areas increased rapidly at the beginning of grain growth, and their increases slowed down drastically after about one day. Similarly, both peak areas increased with increasing keeping time in all the samples, but the $(200)_{\mathrm{Cu}}$ peak was not observed in the $\mathrm{Cu} / \mathrm{Ta}$ and $\mathrm{Cu} / \mathrm{Ti}$ samples even after keeping at $\mathrm{RT}$ for 150 days or more. Thus, the $\mathrm{Cu} / \mathrm{Ta}$ and $\mathrm{Cu} / \mathrm{Ti}$ samples had strong (111) texture.

The degree of texture of the samples was expressed by the area ratio $(\alpha)$ of the

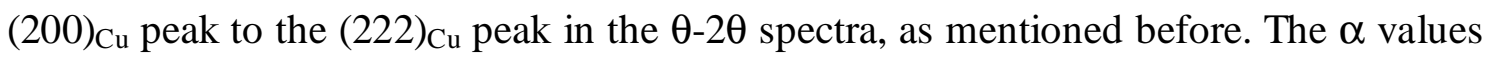
for six samples, $\mathrm{Cu} / \mathrm{Ta}, \mathrm{Cu} / \mathrm{Ta} / \mathrm{TaN}, \mathrm{Cu} /$ sapphire, $\mathrm{Cu} / \mathrm{SiO}_{2}, \mathrm{Cu} / \mathrm{TaN} / \mathrm{Ta}$, and $\mathrm{Cu} / \mathrm{TaN}$, are depicted as a function of the keeping time (Fig. 2). Those for the as-deposited $\mathrm{Cu}$ samples (left-most circles in each plot of Fig. 2) varied with the barrier materials, indicating that the $\mathrm{Cu}$ film texture was determined by the barrier material. The $\alpha$ values for the $\mathrm{Cu} / \mathrm{Ta} / \mathrm{TaN}, \mathrm{Cu} / \mathrm{TaN} / \mathrm{Ta}$, and $\mathrm{Cu} / \mathrm{TaN}$ samples decreased with the keeping time, while those for the barrierless $\mathrm{Cu} /$ sapphire and $\mathrm{Cu} / \mathrm{SiO}_{2}$ samples increased with the keeping time. The $\alpha$ values settled to specific values after sufficient keeping time in all the samples, different values for each sample. For the $\mathrm{Cu} / \mathrm{Ta}$ sample, the $\alpha$ value $(=0)$ did not change at all. 
Since the peak-area increase with keeping time indicates the growth of each $(200)_{\mathrm{Cu}}$ or $(222)_{\mathrm{Cu}}$ grain, the resistivity measurement was the most suitable method to understand average grain growth of the samples. Resistivity increase of the present pure- $\mathrm{Cu}$ films was explained mainly by grain boundary scattering. Figure 3 shows resistivity for the six samples as a function of the keeping time. The resistivity of the as-deposited $\mathrm{Cu}$ films varied with the barrier materials, indicating the as-deposited $\mathrm{Cu}$ grain size was dependent on the barrier material. The resistivity decreased with the keeping time for all the samples (i.e., $\mathrm{Cu}$ grain growth), and the resistivity decrease for each sample showed a similar trend to the $\alpha$ value change (Fig. 2). Thus, the decrease in resistivity for the $\mathrm{Cu} / \mathrm{Ta} / \mathrm{TaN}, \mathrm{Cu} / \mathrm{TaN} / \mathrm{Ta}$, and $\mathrm{Cu} / \mathrm{TaN}$ samples is caused mainly by (111) grain growth, and that for the barrierless $\mathrm{Cu} / \mathrm{sapphire}$ and $\mathrm{Cu} / \mathrm{SiO}_{2}$ samples is caused by (100) grain growth. This suggests that preferential orientation of grains for growth is controlled by the barrier materials. The resistivity reached the minimum value after sufficient keeping time in all the samples, and the minimum resistivity values were different for each sample. For example, the lowest and the highest values were observed for the $\mathrm{Cu} / \mathrm{TaN} / \mathrm{Ta}$ and $\mathrm{Cu} / \mathrm{Ta} / \mathrm{TaN}$ samples, respectively.

The resistivity decrease and $\alpha$ value change with the keeping time showed similar trends, and this suggests that grain growth was controlled by the film texture. While slight amount of $\{511\}$ grains were reported to exist in addition to $\{111\}$ and $\{100\}$ grains in EBSD observation of $\mathrm{Cu}$ films [27-30], unfortunately the (511) Cu peak is out of range of $2 \theta$ in the $\theta-2 \theta$ scan using the $\mathrm{Cu} \mathrm{K}_{\alpha}$-ray, and thus the (511) texture was evaluated by $\theta$ scan, as mentioned before. Typical XRD spectra of the $\theta$ scan $(2 \theta=$ $50.5^{\circ}$ ) for ten samples after keeping at RT for about 200 or more days are shown in Figure 4. The XRD spectra seemed to be divided into three groups: (i) two $(200)_{\mathrm{Cu}}$ 
peaks symmetric about $\theta=25^{\circ}$ (Fig. 4(a)), (ii) three (200) Cu peaks consisting of two peaks symmetric about $\theta=25^{\circ}$ in addition to a peak at $\theta=25^{\circ}$ (Fig. 4(b), and (iii) a single $(200)_{\mathrm{Cu}}$ peak at $\theta=25^{\circ}$ (Fig. 4(c)). The two peaks symmetric about $\theta=25^{\circ}$ and the peak at $\theta=25^{\circ}$ correspond to $\{511\}$ and $\{100\}$ grains, respectively. The figure suggests a correlation between $\{511\}$ grains and $\{100\}$ grains: the volume fraction of $\{511\}$ grains increased with decreasing fraction of $\{100\}$ grains, thereby decreasing the $\alpha$ value. Thus, the $\mathrm{Cu}$ film textures were divided into three groups, consisting of $\{111\}$ and $\{511\}$ mixed grains, $\{111\},\{511\}$, and $\{100\}$ mixed grains, and $\{111\}$ and $\{100\}$ mixed grains, and the $\mathrm{Cu}$ film texture trend can be represented by the $\alpha$ value. Note that $\{111\}$ grains were a main component in all $\mathrm{Cu}$ films.

Based on these results, the relationship among resistivity, $\mathrm{Cu}$ film texture, and keeping time at RT was summarized in Figure 5. The vertical and horizontal axes represent the resistivity of the $\mathrm{Cu}$ films and the $\alpha$ value (i.e., $\mathrm{Cu}$ film texture), respectively. The keeping time change is represented by the symbol change as shown in the inset scale. The resistivity of the as-deposited $\mathrm{Cu}$ films, around keeping time of 30-50 minutes, varied with the $\alpha$ value, indicating the average grain size of as-deposited $\mathrm{Cu}$ films depended on the $\mathrm{Cu}$ film texture (i.e., barrier material), and the initial resistivity was the lowest at $\alpha \sim 0(\mathrm{Cu} / \mathrm{Ta})$. On the other hand, the resistivity reduction rate (i.e., grain growth rate) exhibited the maximum value at the specific $\alpha$ value of $\sim 1.0$ $(\mathrm{Cu} /$ sapphire) due to (100) abnormal grain growth. The resistivity reached the lowest value of $\sim 2.0 \mu \Omega \mathrm{cm}$ at the similar specific $\alpha$ value of $\sim 1.0(\mathrm{Cu} / \mathrm{TaN} / \mathrm{Ta})$ due to (111) abnormal grain growth. These observations indicate that $\mathrm{Cu}$ grain growth at $\mathrm{RT}$ was not dependent on the initial grain size, but was facilitated around the $\alpha$ value of $\sim 1.0$. This suggests that the driving force for the grain growth is not mainly grain boundary energy 
reduction, which is the driving force for normal grain growth, but minimization of crystallographically dependent energies [31]. At the $\alpha$ value of $\sim 1.0$, the $\{111\},\{100\}$, and $\{511\}$ grains coexisted, and such coexistence of three or more orientations of grains is essential for facilitating $\mathrm{Cu}$ grain growth at $\mathrm{RT}$ rather than preference for the (111) or (100) grain growth.

\subsection{Twin Boundary Formation Caused by Grain Growth}

Nano-sized $\mathrm{Cu}$ films are known to have TBs regardless of film preparation techniques such as sputtering and electroplating. As mentioned in the Introduction, the TBs are believed to be useful for nano-sized $\mathrm{Cu}$ interconnects due to increase of electro-migration resistance $[14,15]$. A part of TB formation is believed to be related with the grain growth [18-20], and thus SIM observation was carried out in this study to investigate TB formation during the grain growth. Figure 6 shows typical SIM plan-view images of the $\mathrm{Cu} / \mathrm{TaN}$ samples after keeping at $\mathrm{RT}$ for $14,51,192$, and 263 days. After 14 days, the $\mathrm{Cu}$ film still consisted of a large amount of fine grains and relatively small amount of coarse grains. This suggests that RT grain growth was relatively slow in this sample. As the keeping time increased, the size difference between the coarse and fine grains increased, and amounts of coarse and fine grains increased and decreased, respectively. These observations indicate that such $\mathrm{Cu}$ grain growth pertains particularly to abnormal grain growth. Further grain growth was not observed after 192 days, and the grain growth was believed to be saturated at the keeping time between 51 and 192 days. The tendency of the RT grain growth in the $\mathrm{Cu} / \mathrm{TaN}$ sample is consistent with the resistivity reduction tendency (Fig. 5), and the resistivity reached the minimum value after about 70 days. On the other hand, TBs were 
not obviously observed in the fine grains, but were observed in the coarse grains. This suggests that the TB formation in nano-sized $\mathrm{Cu}$ grains was caused by the grain growth.

Based on similar SIM observations for all the samples, average grain diameter and TB density were evaluated and plotted as a function of the $\alpha$ value in Figures 7(a) and 7(b), respectively. The average grain diameter was about 100 200 nm over a wide range of $\alpha$ values, and found to be maximized at about $500 \mathrm{~nm}$ in a narrow range with the $\alpha$ value of $\sim 1.0$ (Fig. 7(a)). This is consistent with the minimum resistivity in a similar $\alpha$ range (Fig. 5). Similar trend was found in the relation between the average TB density and the $\alpha$ value (Fig. 7(b)), and the TB density was maximized at $\sim 4.6 \times 10^{6} \mathrm{~m}^{-1}$ at the $\alpha$ value of $\sim 1.0$. This suggests that the TB density increased with increasing average grain diameter, and thus the average number of TBs in a grain was plotted as a function of average grain diameter in Fig. 8. The average number of TBs in a grain was estimated by the product of the average TB density and the average grain diameter. A linear relationship was obtained between these values, and the linear function intersected the horizontal axis at about $130 \mathrm{~nm}$. This suggests that the TB number in a grain is proportional to grain size, and TBs might not be formed in grains smaller than a certain size $(\sim 130 \mathrm{~nm})$.

To confirm grain-size dependence on the TB formation, TEM plan-view observation was carried out for the $\mathrm{Cu} / 5 \mathrm{~nm}$-thick $\mathrm{Ta} / \mathrm{SiO}{ }_{2} / \mathrm{Si}$ and $20 \mathrm{~nm}$-thick $\mathrm{Cu} / \mathrm{SiO}_{2} / \mathrm{Si}$ samples. A little grain growth in the $\mathrm{Cu}$ films on the Ta barrier due to strong (111) texture is expected to have a fine microstructure, while facilitating $\mathrm{Cu}$ grain growth on the barrierless $\mathrm{SiO}_{2} / \mathrm{Si}$ substrate is expected to have relatively large grains. For easy plan-view observation, thickness of the Ta barrier in a TEM specimen was reduced to $5 \mathrm{~nm}$ for the $\mathrm{Cu} / 5 \mathrm{~nm}$-thick $\mathrm{Ta} / \mathrm{SiO}_{2} / \mathrm{Si}$ sample. To reduce the $\mathrm{Cu}$ grain size 
after grain growth, the $\mathrm{Cu}$ film thickness was reduced by a factor of about ten for the 20 nm-thick $\mathrm{Cu} / \mathrm{SiO}_{2} / \mathrm{Si}$ samples. The TEM plan-view images of both samples are shown in Figures 9(a) and 9(b). The $\mathrm{Cu} / 5 \mathrm{~nm}$-thick $\mathrm{Ta} / \mathrm{SiO}_{2} / \mathrm{Si}$ sample consisted of $\mathrm{Cu}$ grains with average grain diameter of $\sim 80 \mathrm{~nm}$, and the $\mathrm{Cu}$ grain diameter was distributed in the range between $\sim 50 \mathrm{~nm}$ and $\sim 300 \mathrm{~nm}$ (Fig. 9(a)). Thus, there were some grains larger than $130 \mathrm{~nm}$ in diameter; however, TB was hardly observed in all grains regardless of diameter. In contrast, the $20 \mathrm{~nm}$-thick $\mathrm{Cu} / \mathrm{SiO}_{2} / \mathrm{Si}$ sample consisted of relatively small grains about $50 \mathrm{~nm}$ in diameter (Fig. 9(b)). The TB formation was observed in some of those grains smaller than $130 \mathrm{~nm}$ in diameter. These TEM observation results indicate that the $\mathrm{TB}$ formation in nano-sized $\mathrm{Cu}$ grains was not controlled by grain size, but caused by grain growth. The TBs would not form in the $\mathrm{Cu}$ films with slow growth rate such as $\mathrm{Cu} / \mathrm{Ta}$ samples due to the strong (111) texture, while TBs could form in $\mathrm{Cu}$ films in which grain growth facilitates. The TBs could be annealing twins caused by irregularities in stacking sequence during relatively fast grain growth. Partial dislocations in the TBs can be moved by internal stress in the grains, and such plastic deformation leads to reduction of elastic strain energy in the grains. Therefore, increasing a number of TBs with grain growth is expected to make strain energy relaxation easier.

\subsection{Barrier-Material Effect on Determining Cu Film Texture (10 nm-Thick Films)}

To clarify how and when the texture of the $250 \mathrm{~nm}$-thick $\mathrm{Cu}$ films was determined, texture of the $10 \mathrm{~nm}$-thick $\mathrm{Cu}$ films was investigated using XRD. The texture was similar to that of the $250 \mathrm{~nm}$-thick $\mathrm{Cu}$ films (not shown). This indicates that the texture of the $\mathrm{Cu}$ films was not produced during grain growth, but was made at the early 
beginning of deposition. Typical AFM images of the $\mathrm{Cu}$ films for the $\mathrm{Cu} / \mathrm{Ta}, \mathrm{Cu} / \mathrm{Ta} / \mathrm{TaN}$, $\mathrm{Cu} / \mathrm{TaN} / \mathrm{Ta}, \mathrm{Cu} / \mathrm{SiO}_{2}$, and $\mathrm{Cu} / \mathrm{TaN}$ samples after keeping at $\mathrm{RT}$ for about 10 days are shown in Figure 10. The lateral $\mathrm{Cu}$ layer growth was observed in the $\mathrm{Cu} / \mathrm{Ta}$ and $\mathrm{Cu} / \mathrm{Ta} / \mathrm{TaN}$ samples, while $\mathrm{Cu}$ agglomeration was observed in $\mathrm{Cu} / \mathrm{TaN} / \mathrm{Ta}, \mathrm{Cu} / \mathrm{SiO}_{2}$, and $\mathrm{Cu} / \mathrm{TaN}$ samples, and morphology of $\mathrm{Cu}$ islands became coarse as the $\alpha$ value became larger. This suggests that wettability of the various barriers to $\mathrm{Cu}$ films plays a key role in determining the texture. The good wettability made a continuous $\mathrm{Cu}$ film on the barrier, leading to strong (111) texture.

The (111) texture is reported to be preferential in thin $\mathrm{Cu}$ films, but the (100) texture becomes major in thick $\mathrm{Cu}$ films [8-10, 32, 33]. However, there has not been any report in which correlation between the $\mathrm{Cu}$ film texture and the wettability of various barrier materials was mentioned. In the present study, the texture of $\mathrm{Cu}$ films on various barrier materials seemed to be determined at the early beginning of deposition, and wettability of the barrier materials to the $\mathrm{Cu}$ films determined the texture. Thus, nucleation rates of the $(111)_{\mathrm{Cu}}$ and $(100)_{\mathrm{Cu}}$ grains were calculated as a function of a contact angle, based on thermodynamics during physical vapor deposition [34], and a ratio of calculated nucleation rates between $(111)_{\mathrm{Cu}}$ and $(100)_{\mathrm{Cu}}$ grains as a function of the contact angle is shown in Figure 11. In the calculation, surface energies $\left(\gamma_{v}\right)$ of the $(111)_{\mathrm{Cu}}$ and $(100)_{\mathrm{Cu}}$ grains were, respectively, 1.952 and $2.166 \mathrm{~J} / \mathrm{m}^{2}$ [35], and temperature was $300 \mathrm{~K}$. The chemical free-energy change per unit volume $\left(\Delta G_{\mathrm{v}}\right)$ was not obvious, and in the range between $-1 \times 10^{9} \mathrm{~J} / \mathrm{m}^{3}$ and $-1 \times 10^{10} \mathrm{~J} / \mathrm{m}^{3}$. The elastic strain energy introduced in the $\mathrm{Cu}$ films was ignored for simplicity in calculation. The nucleation rate of the $(111)_{\mathrm{Cu}}$ grains was higher than that of the $(100)_{\mathrm{Cu}}$ grains in the small contact angles (high wettability) in all $\Delta G_{\mathrm{v}}$. This is consistent with the 
experimental results, and thus such correlation between the $\mathrm{Cu}$ film texture and the wettability of various barrier materials can be explained by thermodynamics during physical vapor deposition. Such $\mathrm{Cu}$ film texture at nucleation affects the grain growth, which follows the nucleation.

\section{Conclusions}

$\mathrm{Cu}$ grain growth at $\mathrm{RT}$ was not dependent on initial grain size, but was affected by $\mathrm{Cu}$ film texture ( $\alpha$ value), which depended on barrier material. The $\mathrm{Cu}$ grain growth was rapid on the barrierless $\mathrm{SiO}_{2} / \mathrm{Si}$ substrate, and very slow on the Ta barrier. The growth rate and the average grain diameter after keeping at RT were maximized at the $\alpha$ value of $\sim 1.0$. The $\mathrm{Cu}$ film textures were divided into three groups, consisting of $\{111\}$ and $\{511\}$ mixed grains, $\{111\},\{511\}$, and $\{100\}$ mixed grains, and $\{111\}$ and $\{100\}$ mixed grains, and the $\mathrm{Cu}$ film texture trend can be represented by the $\alpha$ value. The $\{111\}$ grains were a main component in all $\mathrm{Cu}$ films. At the $\alpha$ value of $\sim 1.0$, the $\{111\}$, $\{100\}$, and $\{511\}$ grains coexisted, and such coexistence of three or more orientations of grains is essential for facilitating $\mathrm{Cu}$ grain growth at RT. Similarly, average TB density was maximized at the $\alpha$ value of $\sim 1.0$. The relation also showed that the average number of TBs in a grain was in proportion to the average grain diameter, suggesting a critical grain size to form TBs (about $100 \mathrm{~nm}$ in diameter). However, the TEM observation results indicate that the $\mathrm{TB}$ formation in nano-sized $\mathrm{Cu}$ grains was not controlled by grain size, but caused by grain growth. The TBs would not form in the $\mathrm{Cu}$ films with slow growth rate such as $\mathrm{Cu} / \mathrm{Ta}$ samples due to the strong (111) texture, while TBs could form in $\mathrm{Cu}$ films in which grain growth facilitates. The TBs could be annealing twins caused by irregularities in stacking sequence during relatively fast grain 
growth. The $\mathrm{Cu}$ film texture is concluded to be determined at the early beginning of deposition, and wettability of various barrier materials to the $\mathrm{Cu}$ films plays a key role in determining the film texture.

\section{Acknowledgements}

This work was supported by Research Fellowships of the Japan Society for the Promotion of Science for Young Scientists (Kohama). The author (Ito) would like to thank the Research Foundation For Materials Science. 


\section{REFERENCES}

[1] Bohr MT, El-Mansy YA. IEEE T Electron Dev 1998;45:620.

[2] Zielinski EM, Vinci RP, Bravman JC. J Appl Phys 1994;76:4516.

[3] Vinci RP, Bravman JC. Mater Res Soc Symp P 1993;308:337.

[4] Tracy DP, Knorr DB, Rodbell KP. J Appl Phys 1994;76:2671.

[5] Kuschke WM, Kretschmann A, Keller R-M, Vinci RP, Kaufmann C, Arzt E. J Mater Res 1998;13:2962.

[6] Cao ZH, Lu HM, Meng XK. Mater Chem Phys 2009;117:321.

[7] Ueno K, Ritzdorf T, Grace S. J Appl Phys 1999;86:4930.

[8] Pantleon K, Somers MAJ. J Appl Phys 2006;100:114319.

[9] Pantleon K, Gholinia A, Somers MAJ. Phys Status Solidi A 2008;205:275.

[10] Ying A, Witt C, Jordan-Sweet J, Rosenberg R, Noyan IC. J Appl Phys 2011;109:014907.

[11] Lu L, Shen Y, Chen X, Qian L, Lu K. Sience 2004;304:422.

[12] Shen YF, Lu L, Lu QH, Jin ZH, Lu K. Scripta Mater 2005;52:989.

[13] Sutton AP, Balluffi RW. Interfaces in Crystalline Materials Oxford: Clarendon Press; 1995.

[14] Xu D, Sriram V, Ozolins V, Yang JM, Tu KN, Stafford GR, Beauchamp C, Zienert I, Geisler H, Hofmann P, Zschech E. Microelectron Eng 2008;85:2155.

[15] Chen KC, Wu WW, Liao CN, Chen LJ, Tu KN. Science 2008;321:1066.

[16] Zhang X, Wang H, Chen XH, Lu L, Lu K, Hoagland RG, Misra A. Appl Phys Lett 2006;88:173116.

[17] Zhang X, Anderoglu O, Hoagland RG, Misra A. JOM-J Min Met Mat S 2008;60:75. 
[18] Fullman RL, Fisher JC. J Appl Phys 1951;22:1250.

[19] Dash S, Brown N. Acta Metall Mater 1963;11:1067.

[20] Meyers MA, Murr LE. Acta Metall Mater 1978;26:951.

[21] Mahajan S, Pande CS, Imam MA, Rath BB. Acta Mater 1997;45:2633.

[22] Mahajan S, Chin GY. Acta Metall Mater 1973;21:1353.

[23] Liao XZ, Zhao YH, Srinivasan SG, Zhu YT, Valiev RZ, Gunderov DV. Appl Phys Lett 2004;84:592.

[24] Zhao WS, Tao NR, Guo JY, Lu QH, Lu K. Scripta Mater 2005;53:745.

[25] Yu Q, Shan ZW, Li J, Huang X, Xiao L, Sun J, Ma E. Nature 2010;463:335.

[26] Young RA. The Rietveld Method, New York: Oxford University Press; 1993.

[27] Stangl M, Fletcher A, Acker J, Wendrock H, Wetzig K. J Electron Mater 2007;36:1625.

[28] Courtas S, Gregoire M, Federspiel X, Bicais-Lepinay N, Wyon C. Microelectron Reliab 2006;46:1530.

[29] Yoda R, Nakaue A, Onishi T, Tachibana T. Kobe Steel Engineering Reports 2002;52:66 (in Japanese).

[30] Zielinski EM, Vinci RP, Bravman JC. J Electron Mater 1995;24:1485.

[31] Zielinski EM, Vinci RP, Bravman JC. Appl Phys Lett 1995;67:1078.

[32] Lee H, Wong SS, Lopatin SD. J Appl Phys 2003;93:3796.

[33] Stangl M, Liptak M, Fletcher A, Acker J, Thomas J, Wendrock H, Oswald S, Wetzig K. Microelectron Eng 2008:85;534.

[34] Ohring M. The materials science of thin films, San Diego: Academic Press; 1992

[35] Vitos L, Ruban AV, Skriver HL, Kollar J. Surf Sci 1998;411:186. 
Figure legends

Fig. 1 Portions of XRD spectra around the (a) (200) $\mathrm{Cu}$ and (b) (222) $\mathrm{Cu}$ peaks in the $\theta-2 \theta$ scan, respectively, for the barrierless $\mathrm{Cu} / \mathrm{SiO}_{2}$ sample kept at RT. (c) Peak areas increased for both peaks as a function of keeping time.

Fig. 2 The $\alpha$ values for (a) $\mathrm{Cu} / \mathrm{Ta}$, (b) $\mathrm{Cu} / \mathrm{Ta} / \mathrm{TaN}$, (c) $\mathrm{Cu} / \mathrm{sapphire,} \mathrm{(d)} \mathrm{Cu} / \mathrm{SiO}_{2}$, (e) $\mathrm{Cu} / \mathrm{TaN} / \mathrm{Ta}$, and (f) $\mathrm{Cu} / \mathrm{TaN}$ samples as a function of keeping time.

Fig. 3 The resistivity of $\mathrm{Cu}$ films for (a) $\mathrm{Cu} / \mathrm{Ta}$, (b) $\mathrm{Cu} / \mathrm{Ta} / \mathrm{TaN}$, (c) $\mathrm{Cu} /$ sapphire, (d) $\mathrm{Cu} / \mathrm{SiO}_{2}$, (e) $\mathrm{Cu} / \mathrm{TaN} / \mathrm{Ta}$, and (f) $\mathrm{Cu} / \mathrm{TaN}$ samples as a function of keeping time.

Fig. $4 \mathrm{XRD} \theta$ scan spectra for (a) $\mathrm{Cu} / \mathrm{Ta}, \mathrm{Cu} / \mathrm{Ti}$, and $\mathrm{Cu} / \mathrm{TiN} / \mathrm{Ti}$, (b) $\mathrm{Cu} / \mathrm{Ta} / \mathrm{TaN}$, $\mathrm{Cu} / \mathrm{Ti} / \mathrm{TiN}, \mathrm{Cu} / \mathrm{sapphire}$, and $\mathrm{Cu} / \mathrm{TaN} / \mathrm{Ta}$, and (c) $\mathrm{Cu} / \mathrm{SiO}_{2}, \mathrm{Cu} / \mathrm{TaN}$, and $\mathrm{Cu} / \mathrm{TiN}$ samples after keeping at RT for about 200 or more days. In the $\theta$ scan, $2 \theta$ was set to $50.5^{\circ}$, corresponding to $(200)_{\mathrm{Cu}}$, and $\theta$ was changed in the range between $0^{\circ}$ and $50^{\circ}$. A single peak at about $25^{\circ}$ corresponds to $\{100\}$ grains, and two peaks symmetric about $25^{\circ}$ correspond to $\{511\}$ grains.

Fig. 5 Resistivity reduction with increasing keeping time plotted as a function of the $\alpha$ value (depending on barrier material) for six $\mathrm{Cu}$ samples deposited on different barrier materials. The sample types are indicated in the figure. The change of keeping time is represented by symbol change as shown in the inset scale.

Fig. 6 SIM plan-view images of the $\mathrm{Cu} / \mathrm{TaN}$ sample after keeping at RT for (a) 14, (b) 51, (c) 192, and (d) 263 days. 
Fig. 7 (a) Average grain diameter $(D)$ and (b) average twin boundary density $(n)$ plotted as a function of the $\alpha$ value. These data were obtained from nine $\mathrm{Cu}$ samples deposited on different barrier materials after grain growth settled. The $\alpha$ value for each sample is shown next to the sample type in (b).

Fig. 8 Average number of twin boundaries $(N)$ in a grain plotted as a function of average grain diameter in the $\mathrm{Cu}$ films deposited on the different barrier materials. The $N$ values were estimated by the product of the average twin boundary density $(n)$ and the average grain diameter $(D)$. Inset numbers are the $\alpha$ values.

Fig. 9 TEM plan-view images of the (a) $\mathrm{Cu} / 5 \mathrm{~nm}$-thick $\mathrm{Ta} / \mathrm{SiO}_{2} / \mathrm{Si}$ and (b) $20 \mathrm{~nm}$-thick $\mathrm{Cu} / \mathrm{SiO}_{2} / \mathrm{Si}$ samples.

Fig. 10 AFM images of $\mathrm{Cu}$ films for (a) $\mathrm{Cu} / \mathrm{Ta}$, (b) $\mathrm{Cu} / \mathrm{Ta} / \mathrm{TaN}$, (c) $\mathrm{Cu} / \mathrm{TaN} / \mathrm{TaN}$, (d) $\mathrm{Cu} / \mathrm{SiO}_{2}$, and (e) $\mathrm{Cu} / \mathrm{TaN}$ samples after keeping at $\mathrm{RT}$ for about 10 days.

Fig. 11 Ratio of calculated nucleation rates between $(111)_{\mathrm{Cu}}$ and $(100)_{\mathrm{Cu}}$ grains as a function of the contact angle $(\phi)$. Surface energies $\left(\gamma_{\mathrm{v}}\right)$ of the $(111)_{\mathrm{Cu}}$ and $(100)_{\mathrm{Cu}}$ grains [35], chemical free-energy change per unit volume $\left(\Delta G_{\mathrm{v}}\right)$, and temperature used in the calculations are shown in the figure. 


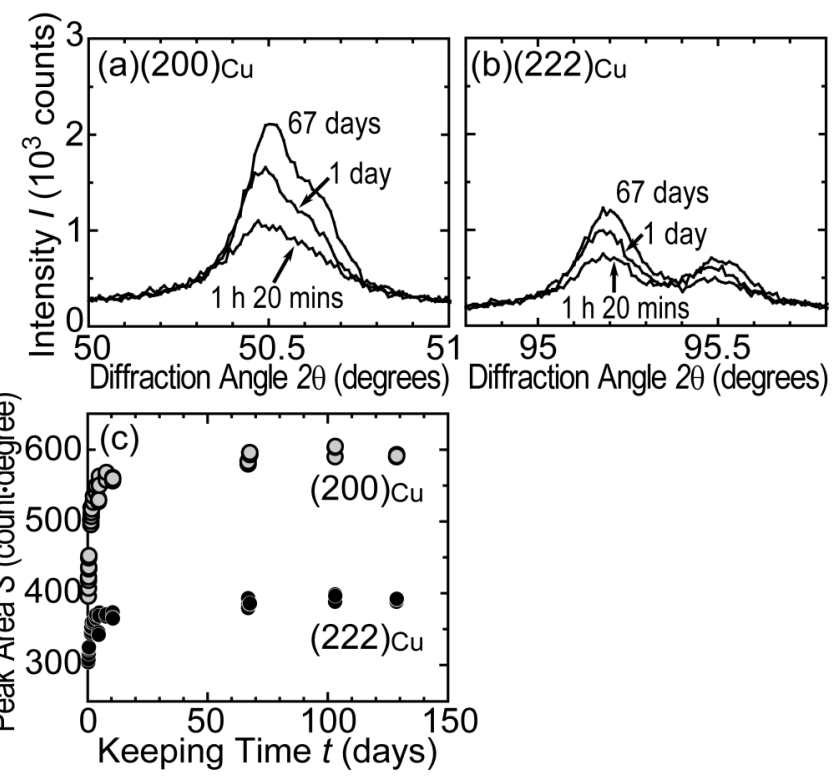

Fig. 1

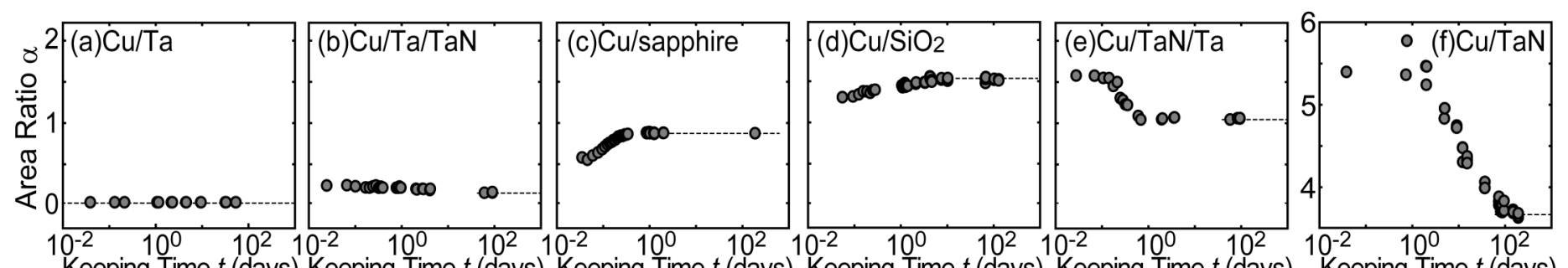

Fig. 2
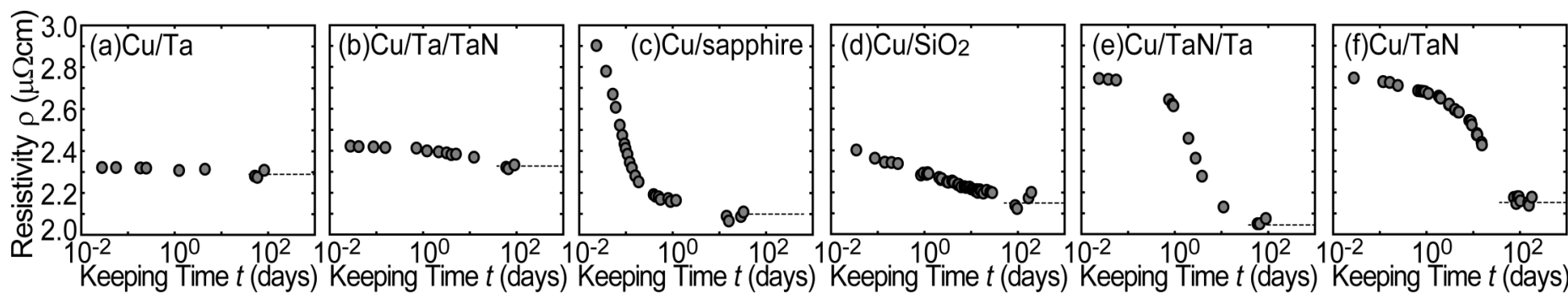

Fig. 3 

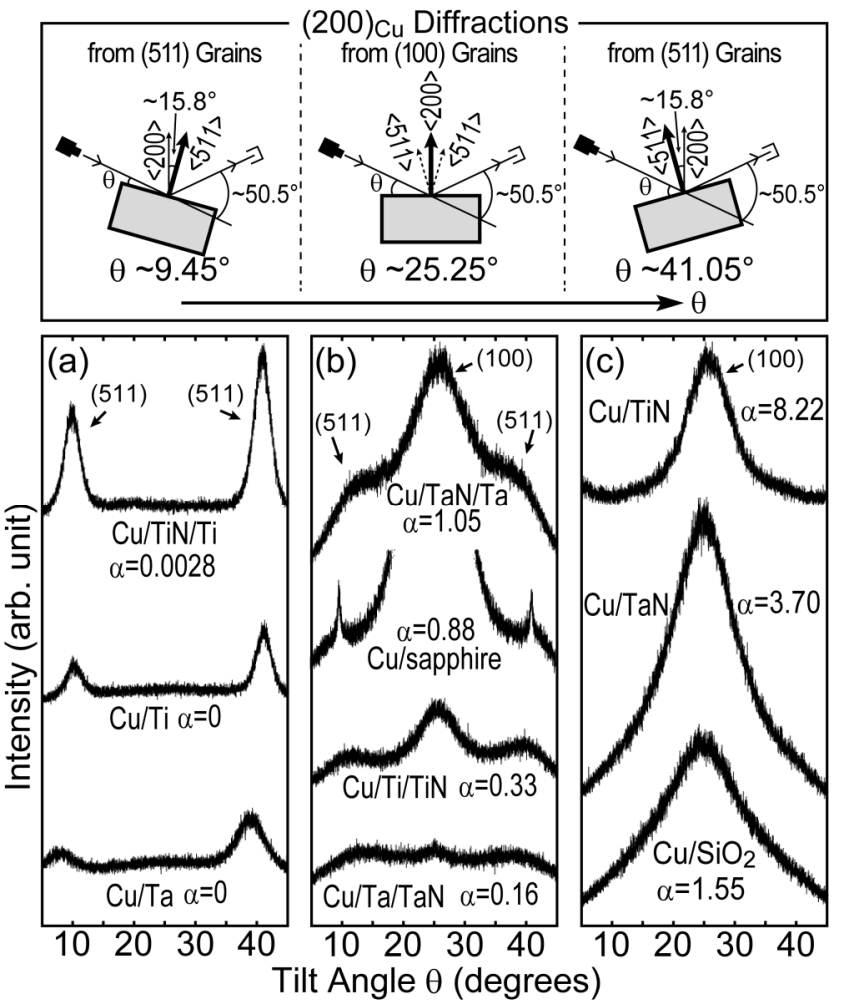

Fig. 4

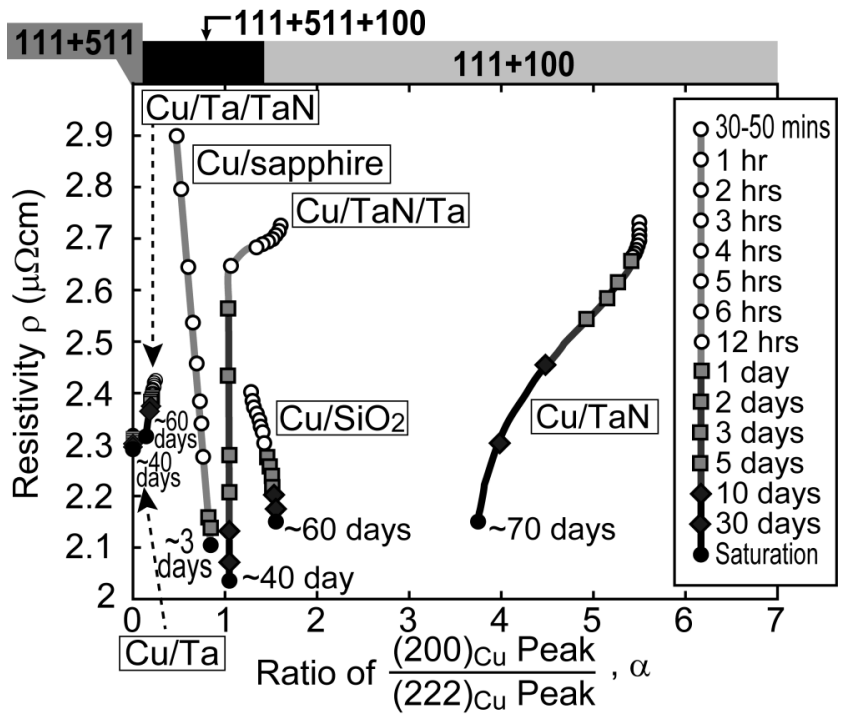

Fig. 5 

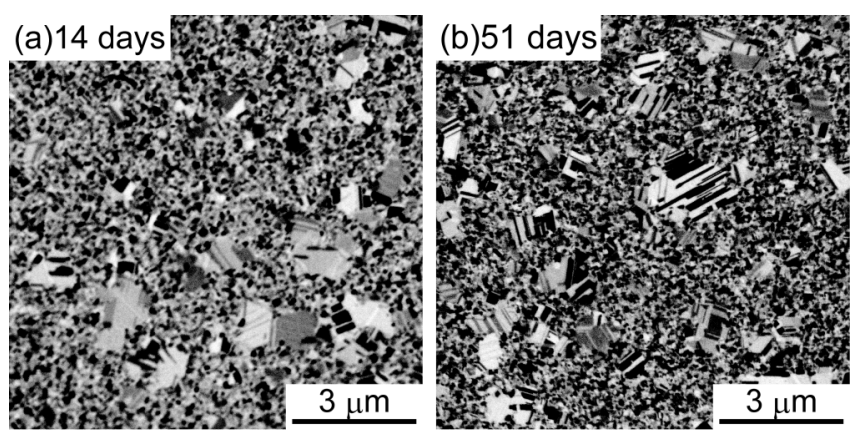

(c)192 days 15 in on

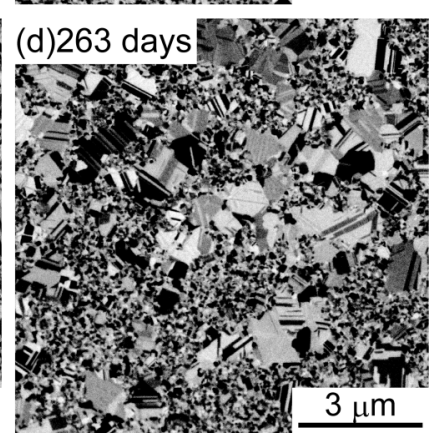

Fig. 6 

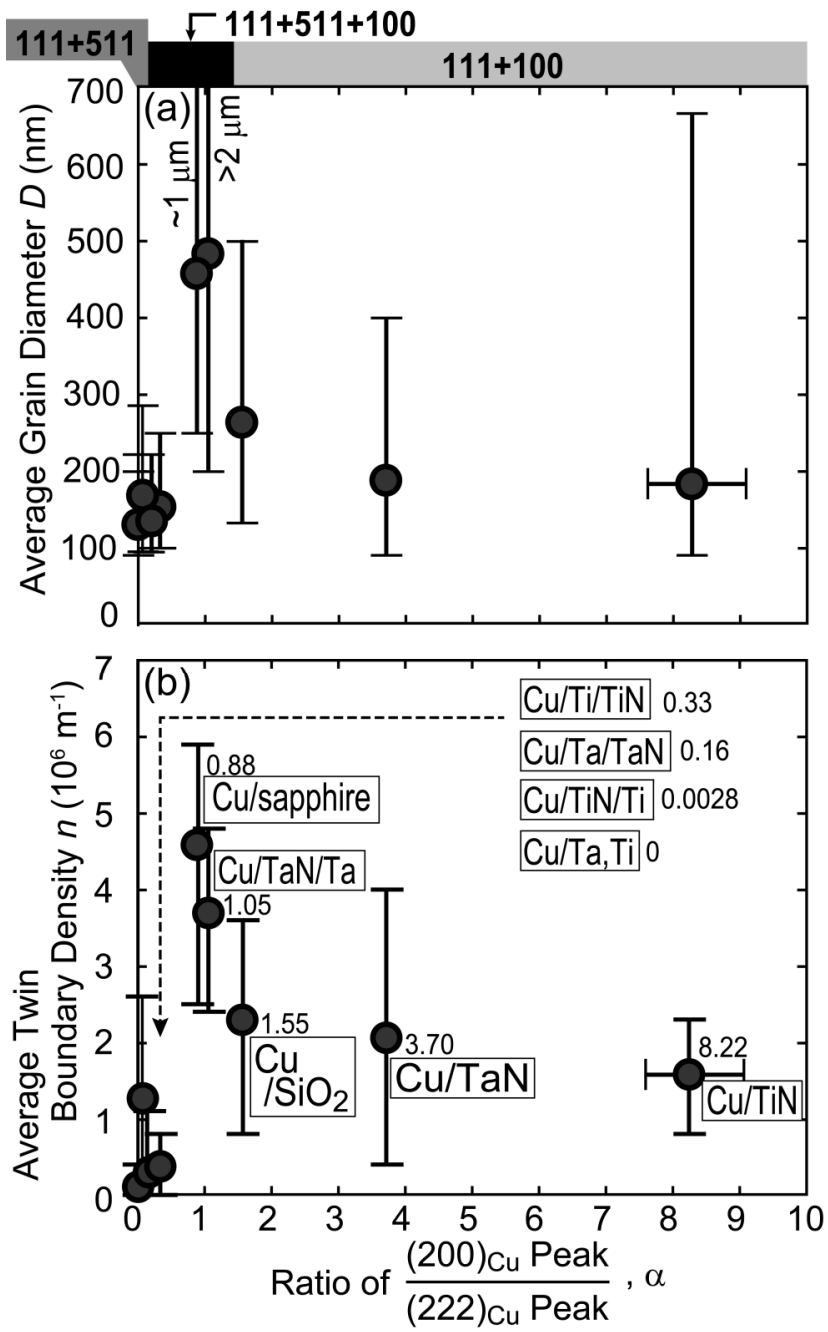

Fig. 7 


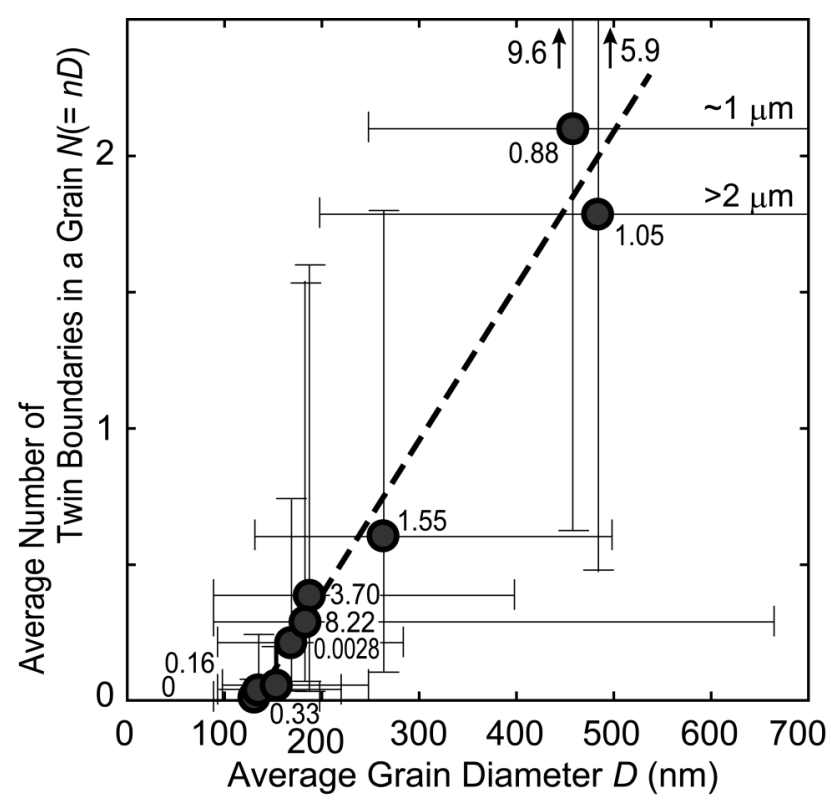

Fig. 8
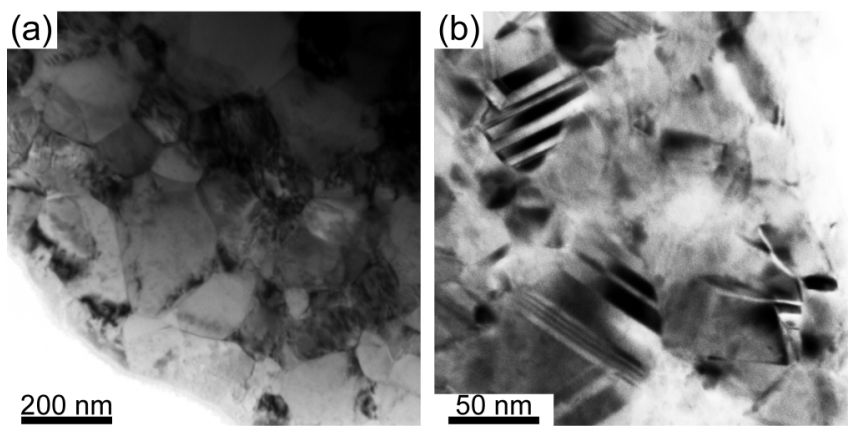

Fig. 9 


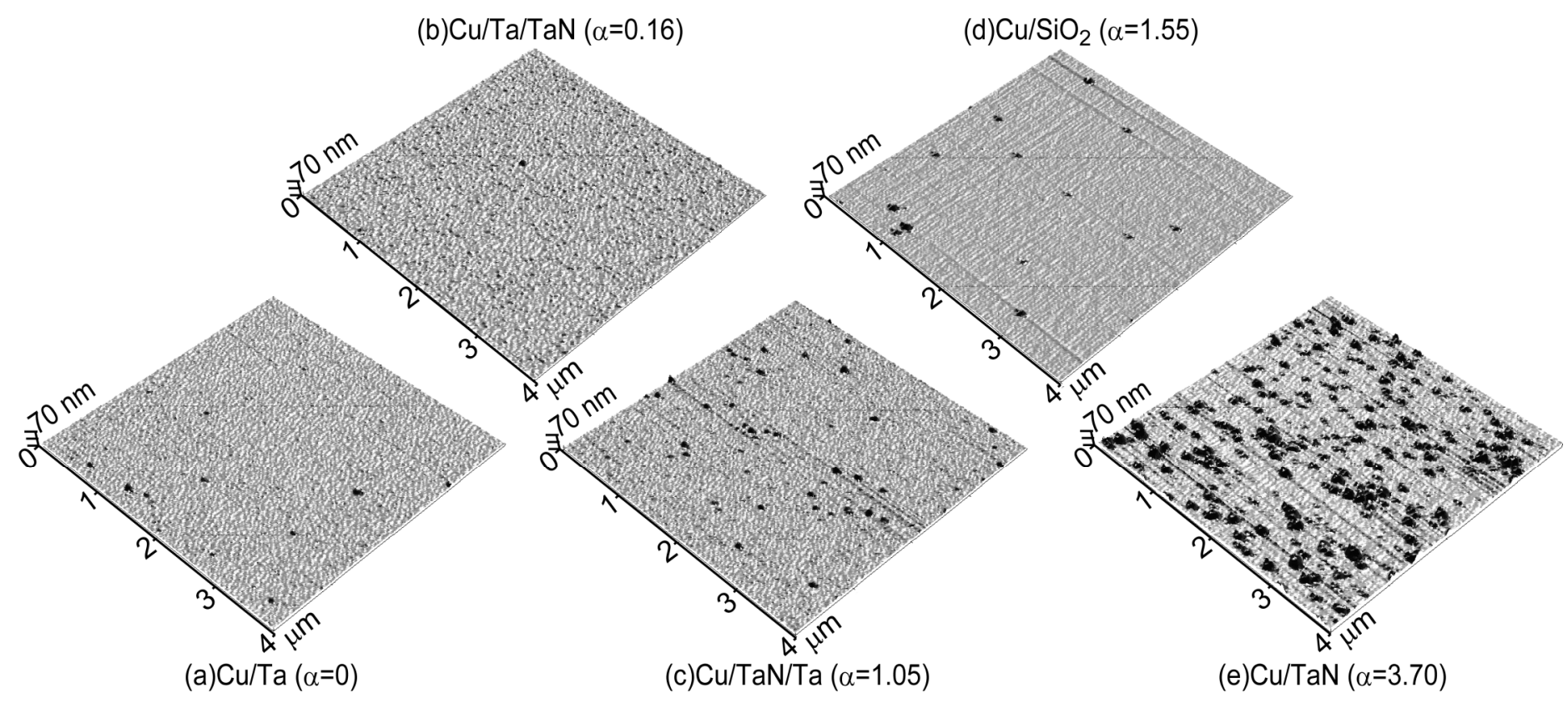

Fig. 10

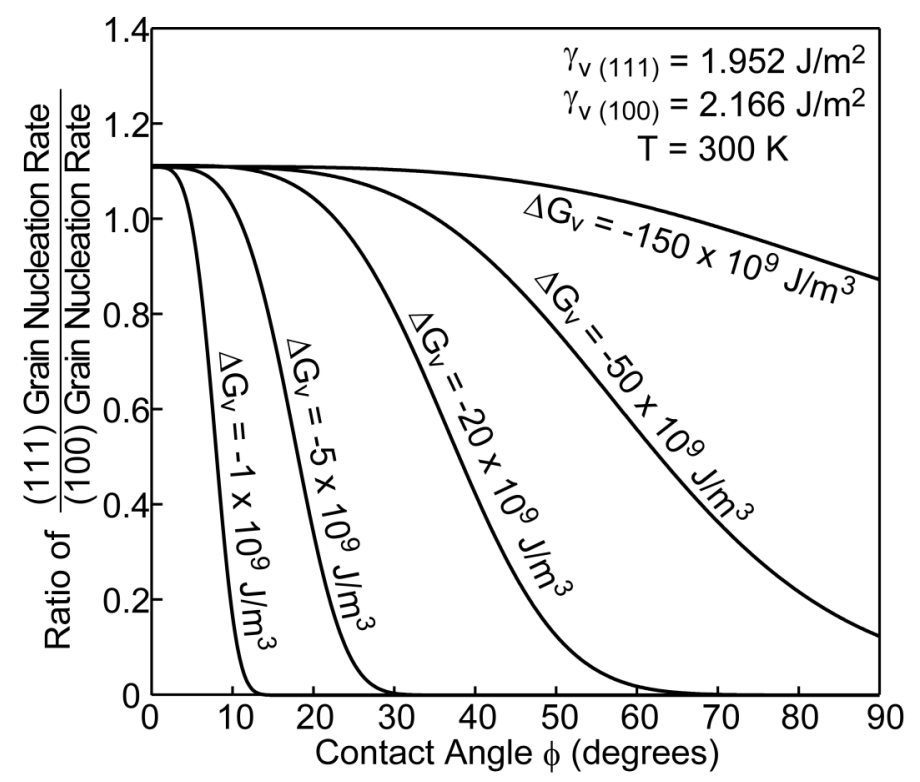

Fig. 11 